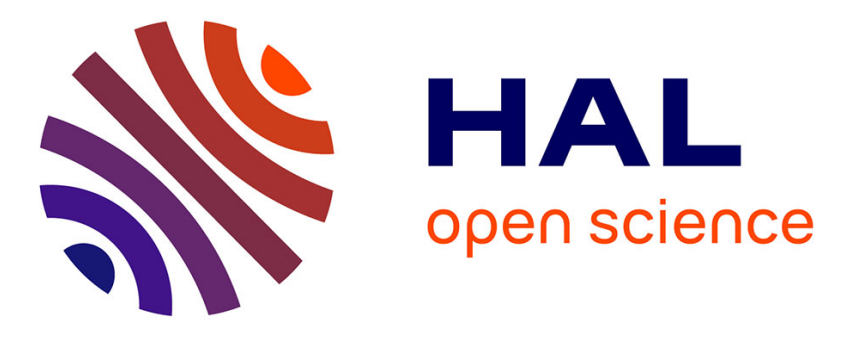

\title{
Synthesis and Electronic Phosphorescence of Dicyanooctatetrayne (NCN) in Cryogenic Matrixes
}

Urszula Szczepaniak, Robert Kolos, Marcin Gronowski, Michèle Chevalier, Jean-Claude Guillemin, Claudine Crépin

\section{- To cite this version:}

Urszula Szczepaniak, Robert Kolos, Marcin Gronowski, Michèle Chevalier, Jean-Claude Guillemin, et al.. Synthesis and Electronic Phosphorescence of Dicyanooctatetrayne (NCN) in Cryogenic Matrixes. Journal of Physical Chemistry A, 2018, 122 (25), pp.5580-5588. 10.1021/acs.jpca.8b02700 . hal01834002

HAL Id: hal-01834002

https://hal-univ-rennes1.archives-ouvertes.fr/hal-01834002

Submitted on 13 Jul 2018

HAL is a multi-disciplinary open access archive for the deposit and dissemination of scientific research documents, whether they are published or not. The documents may come from teaching and research institutions in France or abroad, or from public or private research centers.
L'archive ouverte pluridisciplinaire HAL, est destinée au dépôt et à la diffusion de documents scientifiques de niveau recherche, publiés ou non, émanant des établissements d'enseignement et de recherche français ou étrangers, des laboratoires publics ou privés. 


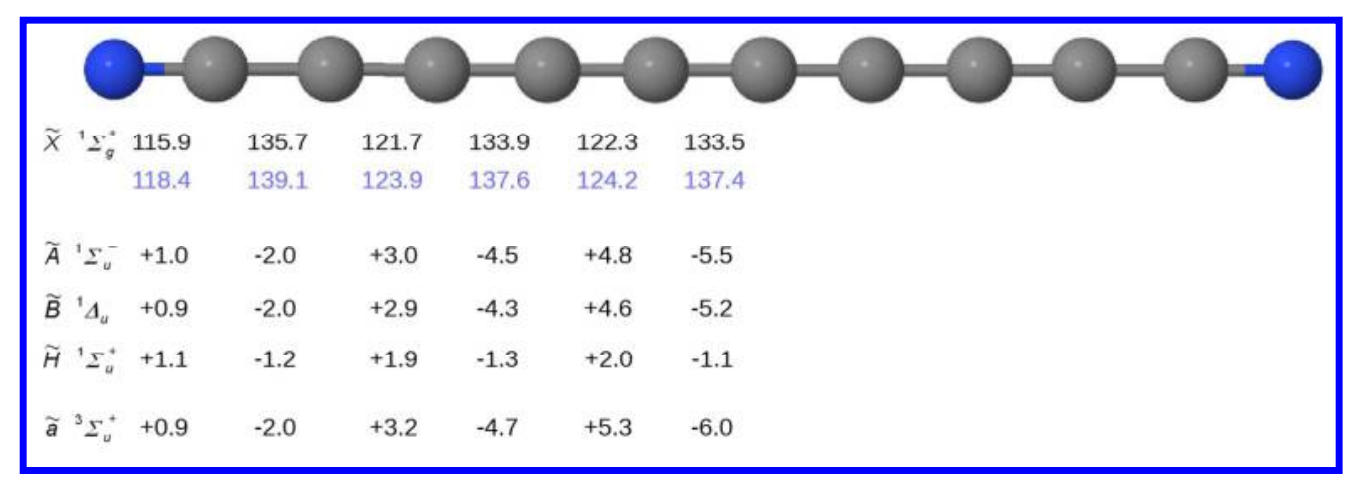

NC10N geometry in its ground and selected excited electronic states... 


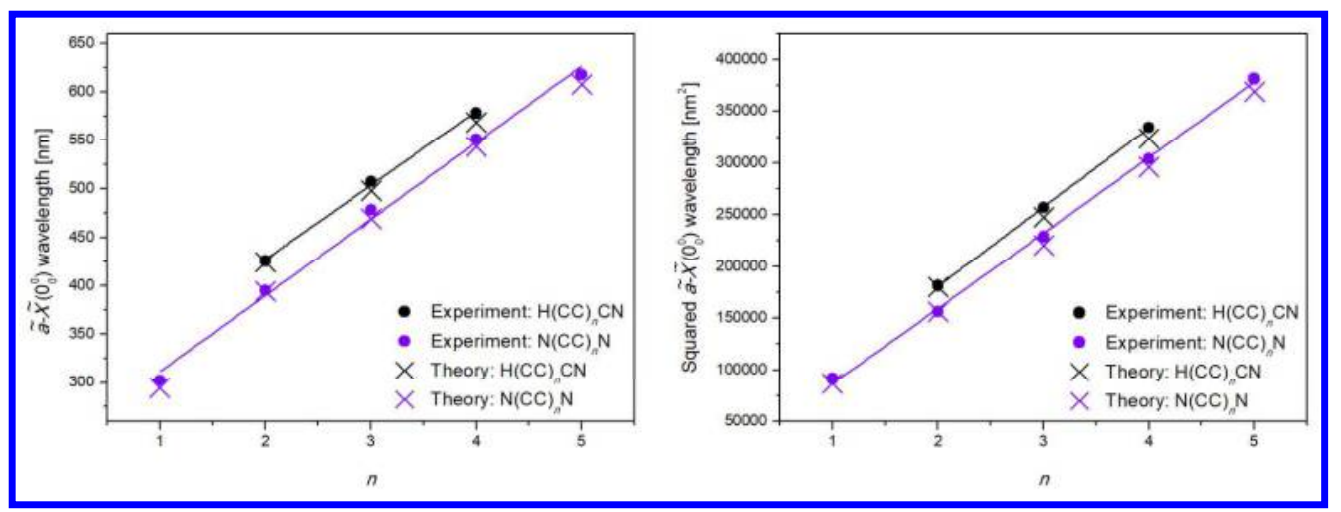

The dependence of phosphorescence wavelength...

$468 \times 171 \mathrm{~mm}(96 \times 96 \mathrm{DPI})$ 


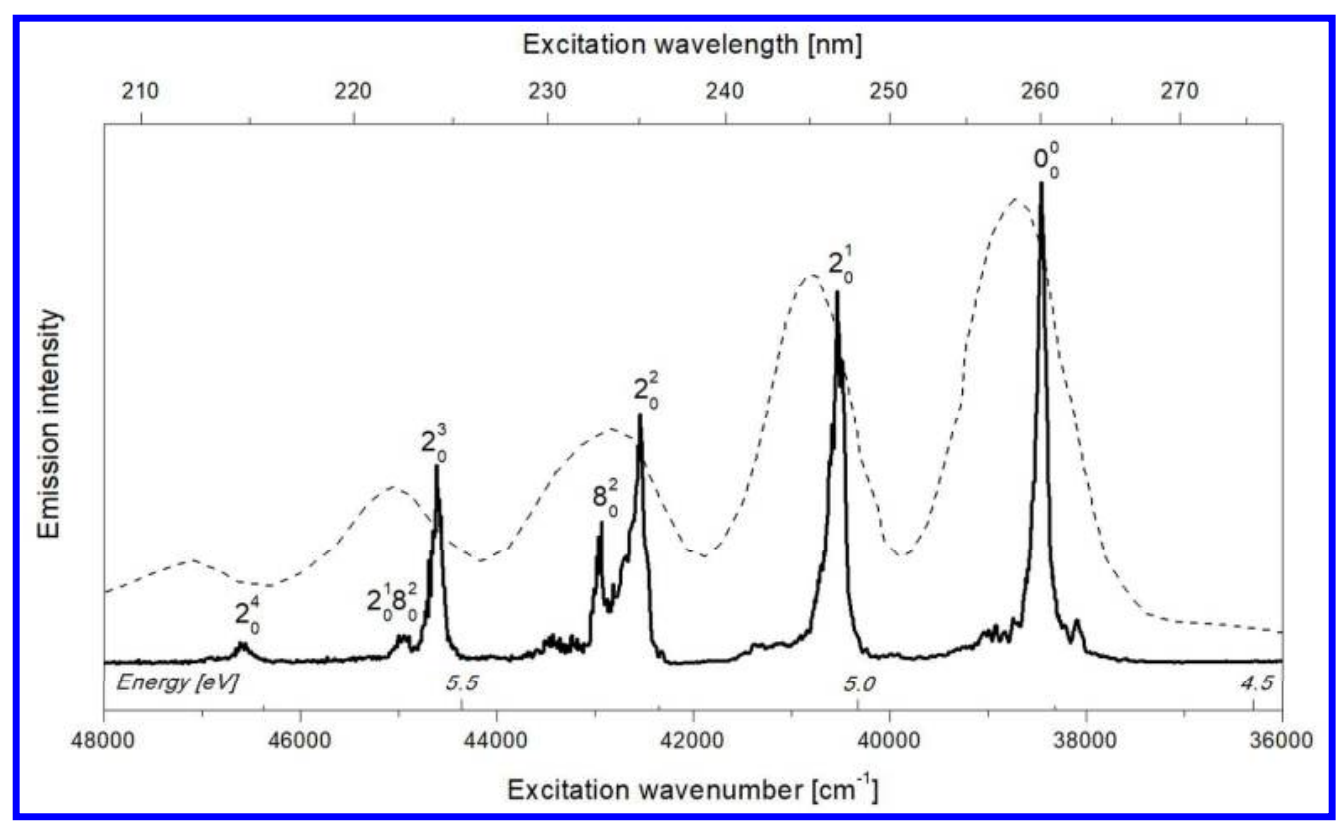

Excitation spectrum of NC10N phosphorescence...

$400 \times 242 \mathrm{~mm}(96 \times 96$ DPI $)$ 


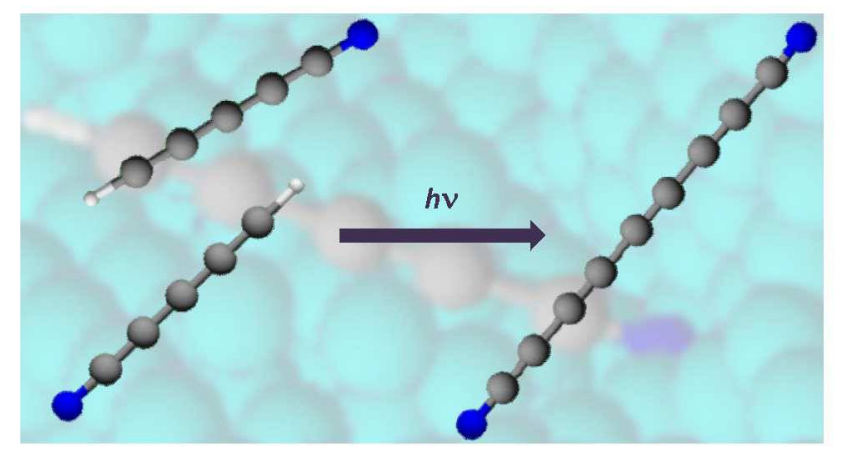

ACS Paragon Plus Environment 
Luminescence, assigned to NC10N phosphorescence, from a previously photolysed (193 nm) Kr/HC5N (1000/1) matrix, excited at $38390 \mathrm{~cm}-1(4.76 \mathrm{eV}, 260.5 \mathrm{~nm})$.

$431 \times 201 \mathrm{~mm}(300 \times 300$ DPI $)$ 
Time evolution of NC10N formation, as monitored by intensity of phosphorescence emitted from irradiated (193 nm) Kr-isolated HC5N. The abscissa represents the irradiation time.

$330 \times 203 \mathrm{~mm}(300 \times 300$ DPI $)$ 


\title{
Synthesis and Electronic Phosphorescence of Dicyanooctatetrayne $\left(\mathrm{NC}_{10} \mathrm{~N}\right)$ in Cryogenic Matrices
}

\author{
Urszula Szczepaniak,, a b * Robert Kołos, ${ }^{\text {b }}$ Marcin Gronowski, ${ }^{\text {b }}$ Michèle Chevalier, ${ }^{\text {a Jean- }}$ \\ Claude Guillemin, ${ }^{c}$ and Claudine Crépin ${ }^{a}$
}

\author{
${ }^{a}$ Institut des Sciences Moléculaires d'Orsay (ISMO), UMR8214, CNRS, Univ. Paris-Sud, Université \\ Paris-Saclay, F-91405 Orsay, FRANCE, \\ ${ }^{b}$ Institute of Physical Chemistry, Polish Academy of Sciences, Kasprzaka 44/52, 01-224 Warsaw, \\ POLAND, \\ ${ }^{c}$ Univ Rennes, Ecole Nationale Supérieure de Chimie de Rennes, CNRS, ISCR - UMR6226, F- \\ 35000 Rennes, France
}

urszula.szczepaniak@u-psud.fr, uszczepaniak@ichf.edu.pl; Present address: Laboratory of Physical Chemistry, ETH Zürich, Vladimir-Prelog Weg 2, CH-8093 Zürich, Switzerland.

\begin{abstract}
Rod-like 1,8-dicyano-octa-1,3,5,7-tetrayne $\left(\mathrm{NC}_{10} \mathrm{~N}\right)$ molecule was synthesized by UV-assisted coupling of rare-gas matrix-isolated cyanobutadiyne $\left(\mathrm{HC}_{5} \mathrm{~N}\right)$ molecules. Detection of $\mathrm{NC}_{10} \mathrm{~N}$ molecule was possible due to its strong orange-red (origin at $618 \mathrm{~nm}$ ) electronic luminescence. Excitation spectra of this emission $\left(\tilde{a}^{3} \Sigma_{\mathrm{u}}{ }^{+}-\tilde{X}^{1} \Sigma_{\mathrm{g}}{ }^{+}\right.$phosphorescence) gave access to studying the fully allowed $\widetilde{H}^{1} \Sigma_{\mathrm{u}}^{+}-\widetilde{X}^{1} \Sigma_{\mathrm{g}}^{+} \mathrm{UV}$ system of $\mathrm{NC}_{10} \mathrm{~N}$. The identification of observed spectral features was assisted with quantum chemical calculations. Certain regularities shaping the electronic spectroscopy of $\mathrm{NC}_{2 n} \mathrm{~N}$ molecules have been discussed.
\end{abstract}

\section{INTRODUCTION}

Hydrogenless centrosymmetric dicyanopolyyne chains $\left(\mathrm{NC}_{2 n} \mathrm{~N}\right)$ constitute a unique series of welldefined linear molecules of closed-shell electronic structure. They are kinetically more stable, at least as judged by the first elements of the series, than respective isoelectronic species of the related monocyanopolyyne $\left(\mathrm{HC}_{2 n+1} \mathrm{~N}\right)$ or polyyne $\left(\mathrm{HC}_{2 n} \mathrm{H}\right)$ series. ${ }^{1}$ For example, while working with dicyanoethyne $\left(\mathrm{NC}_{4} \mathrm{~N}\right)^{2}$ we could observe that it is much less susceptible to decomposition (by polymerization) than cyanobutadiyne $\left(\mathrm{HC}_{5} \mathrm{~N}\right)^{3}$ or hexatriyne $\left(\mathrm{HC}_{6} \mathrm{H}\right) .{ }^{4}$ Rod-like $\mathrm{NC}_{2 n} \mathrm{~N}$ chains, with their highly conjugated bonding and the ensuing semiconductive properties, are interesting from purely theoretical/spectroscopic point of view, but potential applications, as nanowires, ${ }^{5}$ were also hypothesized. Moreover, dicyanopolyynes are molecules of astrochemical interest. ${ }^{6}$ However, while the presence of $\mathrm{HC}_{2 n+1} \mathrm{~N}$ nitriles in interstellar gas clouds has been confirmed with microwave spectroscopy up to $n=4,,^{7-16}$ little is known about centrosymmetric $\mathrm{NC}_{2 n} \mathrm{~N}$ molecules in any extraterrestrial sources, apart from a tentative identification ${ }^{17}$ of dicyanoacetylene $\left(\mathrm{NC}_{4} \mathrm{~N}\right)$ in the atmosphere of the Saturn's moon Titan. Aerosols build-up from related, highly unsaturated carbon- 
42 nitrogen polymers may contribute to the Titan's characteristic orange haze. ${ }^{19}$ Some information

43 about $\mathrm{NC}_{2 \mathrm{n}} \mathrm{N}$ molecules in space can be obtained by observation of their protonated forms. ${ }^{18}$

44 Certain molecular properties were theoretically predicted for $\mathrm{NC}_{2 n} \mathrm{~N}$ molecules, including the geometry, vibrational modes, and electronic transition energies; some of these were derived up to $n$ $=8 .^{5,20-22} \mathrm{NC}_{2} \mathrm{~N}, \mathrm{NC}_{4} \mathrm{~N}$, and (to a lesser extent) $\mathrm{NC}_{6} \mathrm{~N}$ are rather well experimentally characterized, being available in macroscopic quantities via preparative organic synthesis. In particular, these are known to emit strong phosphorescence under cryogenic isolation conditions. ${ }^{21,23,24}$ Experimental data reported for larger $(n>3)$ members of the series are limited to $\mathrm{NMR}$ spectroscopy (in $\mathrm{CDCl}_{3}, n$ $\leq 9)$, ${ }^{1}$ IR spectra of solid substances in $\mathrm{NaCl}(n \leq 9)$, ${ }^{1}$ electronic absorption spectra in liquid organic solvents ${ }^{1,25-27}(n \leq 9)$ and in the gas phase $(n=8),{ }^{5}$ and low temperature electronic phosphorescence $(n=4) .^{21,22,24}$ Very recently, traces of a long-lived luminescence attributable to $\mathrm{NC}_{10} \mathrm{~N}$ were observed by us in a study primarily devoted to $\mathrm{HC}_{9} \mathrm{~N}$ spectroscopy. ${ }^{28}$ In each of these cases, electronic emission was characterized by at least one prominent vibronic progression with a spacing of $2000-2300 \mathrm{~cm}^{-1}$, typical of $\mathrm{CC}$ or $\mathrm{CN}$ triple-bond stretching modes. Luminescence was also observed for $\mathrm{C}_{4} \mathrm{~N}_{2}{ }^{+}, \mathrm{C}_{6} \mathrm{~N}_{2}{ }^{+}$, and $\mathrm{C}_{8} \mathrm{~N}_{2}{ }^{+}$in cryogenic Ne matrices. ${ }^{29,30}$

Here we report on synthesizing $\mathrm{NC}_{10} \mathrm{~N}$ (1,8-dicyano-octa-1,3,5,7-tetrayne or deca-2,4,6,8-tetrayne1,8-dinitrile) in noble gas ( $\mathrm{Ar}$ and $\mathrm{Kr}$ ) matrices, using the method of cryogenic photochemical coupling, already proved useful for $\mathrm{C}_{6} \mathrm{~N}_{2},{ }^{21}$ as well as for the monocyanopolyynes $\mathrm{HC}_{5} \mathrm{~N},{ }^{21,31}$ $\mathrm{HC}_{7} \mathrm{~N},{ }^{32}$ and $\mathrm{HC}_{9} \mathrm{~N} .{ }^{28}$ Since $\mathrm{NC}_{6} \mathrm{~N}$ appeared in photolysed matrices doped with $\mathrm{HC}_{3} \mathrm{~N}^{21}{ }^{21} \mathrm{NC}_{10} \mathrm{~N}$ formation from $\mathrm{HC}_{5} \mathrm{~N}$ was anticipated, even though $\mathrm{HC}_{5} \mathrm{~N}$ molecules are larger than $\mathrm{HC}_{3} \mathrm{~N}$ and their movement in a matrix is even more restricted. The spectroscopic identification of products has been supported using density functional theory calculations of electronic and vibrational energy levels.

\section{EXPERIMENTAL METHODS}

66 Experimental details regarding matrix preparation and spectroscopic characterization of the 67 photochemical products are only briefly summarized here, as these were recently described in our 68 reports on $\mathrm{HC}_{9} \mathrm{~N}^{28}$ and $\mathrm{CH}_{3} \mathrm{C}_{7} \mathrm{~N}^{33}$

69 Precursor molecule, $\mathrm{HC}_{5} \mathrm{~N}$, was prepared with the method developed by Trolez and Guillemin. ${ }^{3}$ It was purified by pumping while kept at $\mathrm{T}<200 \mathrm{~K}$, directly before the experiment. Solid krypton has

71 been shown to permit strong and spectrally well-resolved luminescence of embedded 72 cyanopolyynes. ${ }^{21,22}$ Therefore, it was used here (4.0, Messer), along with, more commonly applied 73 in matrix-isolation spectroscopy, argon (6.0, Messer).

$74 \mathrm{HC}_{5} \mathrm{~N}$ molecules were mixed with noble gases at a ratio of 1:1000 to 1:500. The mixture was 75 subsequently trapped on a sapphire substrate window held at either $30 \mathrm{~K}(\mathrm{Kr})$ or at $22 \mathrm{~K}$ (Ar) inside 76 a closed-cycle helium refrigerator equipped with external $\mathrm{CaF}_{2}$ windows. The typical amount of 77 deposited gas was 6-8 mmol. Composition of the samples was verified with FTIR spectroscopy. The 78 photochemical transformations were induced with UV irradiation of cryogenic matrices $(30 \mathrm{~K}$ for $79 \mathrm{Kr} ; 22 \mathrm{~K}$ for Ar) by means of an $\operatorname{ArF}$ excimer laser $\left(193 \mathrm{~nm}, 10 \mathrm{~Hz},<5 \mathrm{~mJ} / \mathrm{cm}^{2}\right.$ per pulse). Spectra 
80

81

82

83

84

were recorded for a sample kept at $7 \mathrm{~K}$. Of note, the formation of $\mathrm{NC}_{10} \mathrm{~N}$ was also observed in experiments aimed at $\mathrm{HC}_{9} \mathrm{~N}$ and $\mathrm{CH}_{3} \mathrm{C}_{7} \mathrm{~N}$, involving $\mathrm{HC}_{5} \mathrm{~N}$ co-deposited with, respectively, diacetylene (see Ref. ${ }^{28}$ ) and methylacetylene (see Ref. ${ }^{33}$ ). Certain thus far unpublished results coming from these studies are included in the present report.

The identification of photolysis products relied on selectively excited electronic luminescence, by means of an optical parametric oscillator (OPO). Dispersed phosphorescence was searched for in the $380-800 \mathrm{~nm}$ range with a resolution of approx. $0.04 \mathrm{~nm}$. The observed emission was also registered as a function of the excitation wavelength $(192-280 \mathrm{~nm})$, yielding phosphorescence excitation spectra. Time synchronization between laser pulses $(193 \mathrm{~nm}$ excimer laser for photolysis and a tunable OPO for spectroscopy), as well as the acquisition of phosphorescence signals (with a CCD camera) were provided by a home-made triggering device.

\section{COMPUTATIONAL DETAILS}

Although certain theoretical studies devoted to $\mathrm{NC}_{10} \mathrm{~N}$ have already been reported, ${ }^{20}$ these did not comprise excited electronic states. Here, experiments implicated electronic excitation, respective quantum chemical calculations were therefore performed; for consistency, predictions concerning the ground electronic state have also been included.

Quantum chemical computations were carried out mainly at the density functional theory (DFT) ${ }^{34}$ level, with the GAUSSIAN 09 (Rev. B. 01) ${ }^{35}$ program package. Time-dependent methodologies ${ }^{36-38}$ and the B3PW91 functional of Perdew and Wang ${ }^{39-42}$ were applied for singlet excited electronic states. Energetic separations between the ground and the lowest triplet states were derived employing the CAM-B3LYP ${ }^{43}$ functional. Computations made use of the aug-cc-pVTZ ${ }^{44,45}$ basis set. This approach supplied molecular geometries, harmonic vibrational wavenumbers, and energies of transitions from the ground to excited electronic states. Additionally, IR absorption intensity and Raman activity values were predicted for the ground electronic state (B3PW91/aug-cc-pVTZ). To account for anharmonicity and inherent deficiencies of the involved theoretical approach, vibrational wavenumbers were scaled with the factor of $0.96 .{ }^{46,47}$ Linearity of the carbon-nitrogen backbone in excited singlet electronic states was verified by performing CIS/aug-cc-pVDZ ${ }^{44,45,48}$ optimizations (starting from a bent structure) and by looking, at both CIS and DFT levels, for the degeneracy of bending modes. Optimized structures were also checked for the absence of imaginary vibrational frequencies. Vertical excitation energies, together with the corresponding oscillator strengths, were additionally derived at the ab-initio level $\mathrm{CC}^{49-52}$ (cc-pVTZ basis set), using the Dalton2016 $6^{53,54}$ software. Chemcraft ${ }^{55}$ program was employed in the preparation of input data and for the visualization of results. However, the CC2 approach applied here can not be regarded as inherently more accurate than DFT, since our $\mathrm{CC} 2$ calculations were performed solely within the vertical approximation. 
A. Theoretical predictions

119 Theoretical results concerning the electronic states of $\mathrm{NC}_{10} \mathrm{~N}$ are collected in Table 1 and Figure 1. 120 The first fully allowed electronic excitation of a ground-state molecule is predicted at $4.65 \mathrm{eV}$ (267 $121 \mathrm{~nm}$ ). We have checked that the energy of the next allowed transition is around $6.2 \mathrm{eV}$ (vertical 122 approximation), and no transition with oscillator strength similar to that characterizing $\widetilde{H}-\tilde{X}$ is 123 predicted up to around $7 \mathrm{eV}$. Formerly reported UV-Vis absorption of $\mathrm{NC}_{10} \mathrm{~N}$ in acetonitrile ${ }^{1}$ and in $124 n$-octane solution ${ }^{25}$ is energetically close to the currently predicted $\widetilde{H}-\tilde{X}$ excitation. Electronic 125 structures characterizing states $\tilde{A}, \widetilde{B}, \tilde{a}$, and $\widetilde{H}$ originate mainly in the HOMO-LUMO excitation. $\widetilde{H}$ 126 state features the smallest deviation from the ground state geometry (see Figure 1), just as reported 127 for the analogous $(\tilde{E})$ state of $\mathrm{HC}_{9} \mathrm{~N}^{28}$ Transitions to the three lowest excited states $(\tilde{A}, \tilde{B}$, and $\tilde{a})$ 128 result in mutually similar changes of geometry (in analogy to what was observed for several alike 129 carbon-nitrogen chains ${ }^{28,33,56}$ ).

130 Table 1. Theoretical Predictions ${ }^{a}$ of Energy (in $\mathrm{eV}$ ), Wavelength (in $\mathrm{nm}$ ), and Oscillator Strength $(f)$ for 131 Electronic Transitions of $\mathbf{N C}_{10} \mathbf{N}$ Departing from the $\widetilde{X}^{1} \Sigma_{\mathrm{g}}{ }^{+}$State $^{b}$.

\begin{tabular}{|c|c|c|c|c|c|c|}
\hline & & \multicolumn{2}{|c|}{ CC2/cc-pVTZ } & \multicolumn{3}{|c|}{ DFT } \\
\hline State & $\begin{array}{c}\text { Dominant } \\
\text { orbital } \\
\text { excitation }\end{array}$ & $\begin{array}{c}\text { Vertical } \\
\text { transition } \\
\text { energy } \\
\text { (wavelength) }\end{array}$ & $f$ & $\begin{array}{c}\text { Vertical } \\
\text { transition } \\
\text { energy } \\
\text { (wavelength) }\end{array}$ & $f^{c}$ & $\begin{array}{l}0-0 \text { transition } \\
\text { energy } \\
\text { (wavelength) }\end{array}$ \\
\hline$\tilde{A}^{1} \Sigma_{\mathrm{u}}^{-}$ & $3 \pi_{\mathrm{g}} \rightarrow 1 \pi_{\mathrm{u}}{ }^{*}$ & $3.27(379)$ & 0 & $2.62(473)$ & 0 & $2.18(569)$ \\
\hline$\widetilde{B}^{1} \Delta_{\mathrm{u}}$ & $3 \pi_{\mathrm{g}} \rightarrow 1 \pi_{\mathrm{u}}{ }^{*}$ & $3.39(366)$ & 0 & $2.71(458)$ & 0 & $2.30(539)$ \\
\hline$\tilde{C}^{1} \Sigma_{\mathrm{g}}^{-}$ & $3 \pi_{\mathrm{u}} \rightarrow 1 \pi_{\mathrm{u}}{ }^{*}$ & $4.64(267)$ & 0 & $4.01(309)$ & 0 & $3.74(332)$ \\
\hline$\widetilde{D}^{1} \Delta_{\mathrm{g}}$ & $3 \pi_{\mathrm{u}} \rightarrow 1 \pi_{\mathrm{u}}{ }^{*}$ & $4.84(256)$ & 0 & $4.16(298)$ & 0 & $3.90(318)$ \\
\hline$\widetilde{E}^{1} \Sigma_{\mathrm{g}}^{-}$ & $3 \pi_{\mathrm{g}} \rightarrow 1 \pi_{\mathrm{g}}{ }^{*}$ & $5.92(209)$ & 0 & $4.81(258)$ & 0 & $4.53(274)$ \\
\hline$\tilde{F}^{1} \Delta_{\mathrm{g}}$ & $3 \pi_{\mathrm{g}} \rightarrow 1 \pi_{\mathrm{g}}{ }^{*}$ & $6.01(206)$ & 0 & $4.82(257)$ & 0 & $4.54(273)$ \\
\hline$\tilde{G}^{1} \Sigma_{\mathrm{g}}^{+}$ & $\begin{array}{l}3 \pi_{\mathrm{u}} \rightarrow 1 \pi_{\mathrm{u}}{ }^{*} \\
3 \pi_{\mathrm{g}} \rightarrow 1 \pi_{\mathrm{g}}{ }^{*}\end{array}$ & $5.32(233)$ & 0 & $4.84(256)$ & 0 & $4.56(272)$ \\
\hline$\widetilde{H}^{1} \Sigma_{\mathrm{u}}^{+}$ & $3 \pi_{\mathrm{g}} \rightarrow 1 \pi_{\mathrm{u}}{ }^{*}$ & $5.30(234)$ & 6.1 & $4.80(258)$ & 5.2 & $4.65(267)$ \\
\hline$\tilde{a}^{3} \Sigma_{\mathrm{u}}^{+}$ & $3 \pi_{\mathrm{g}} \rightarrow 1 \pi_{\mathrm{u}}{ }^{*}$ & $2.59(479)$ & & & & $2.04(608)$ \\
\hline
\end{tabular}

${ }^{a}$ Obtained with DFT (B3PW91/aug-cc-pVTZ for excited singlet states, CAM-B3LYP/aug-cc-pVTZ for $\tilde{a}^{3} \Sigma_{\mathrm{u}}{ }^{+}$) and $a b$ 133 initio (CC2/cc-pVTZ) methods.

$134{ }^{b}$ Ground state electronic configuration is [core] $\left(1 \sigma_{\mathrm{u}}\right)^{2}\left(1 \sigma_{\mathrm{g}}\right)^{2}\left(2 \sigma_{\mathrm{g}}\right)^{2}\left(2 \sigma_{\mathrm{u}}\right)^{2}\left(3 \sigma_{\mathrm{g}}\right)^{2}\left(3 \sigma_{\mathrm{u}}\right)^{2}\left(4 \sigma_{\mathrm{g}}\right)^{2}\left(4 \sigma_{\mathrm{u}}\right)^{2}\left(5 \sigma_{\mathrm{g}}\right)^{2}\left(5 \sigma_{\mathrm{u}}\right)^{2}\left(6 \sigma_{\mathrm{g}}\right)^{2}$ $135 \quad\left(1 \pi_{\mathrm{u}}\right)^{4}\left(1 \pi_{\mathrm{g}}\right)^{4}\left(2 \pi_{\mathrm{u}}\right)^{4}\left(6 \sigma_{\mathrm{u}}\right)^{2}\left(7 \sigma_{\mathrm{g}}\right)^{2}\left(2 \pi_{\mathrm{g}}\right)^{4}\left(3 \pi_{\mathrm{u}}\right)^{4}\left(3 \pi_{\mathrm{g}}\right)^{4}\left(1 \pi_{\mathrm{u}}^{*}\right)^{0}\left(1 \pi_{\mathrm{g}}^{*}\right)^{0}\left(1 \sigma_{\mathrm{g}}\right)^{*}$.

$136{ }^{c} 0$ indicates $f<5 \cdot 10^{-5}$. 


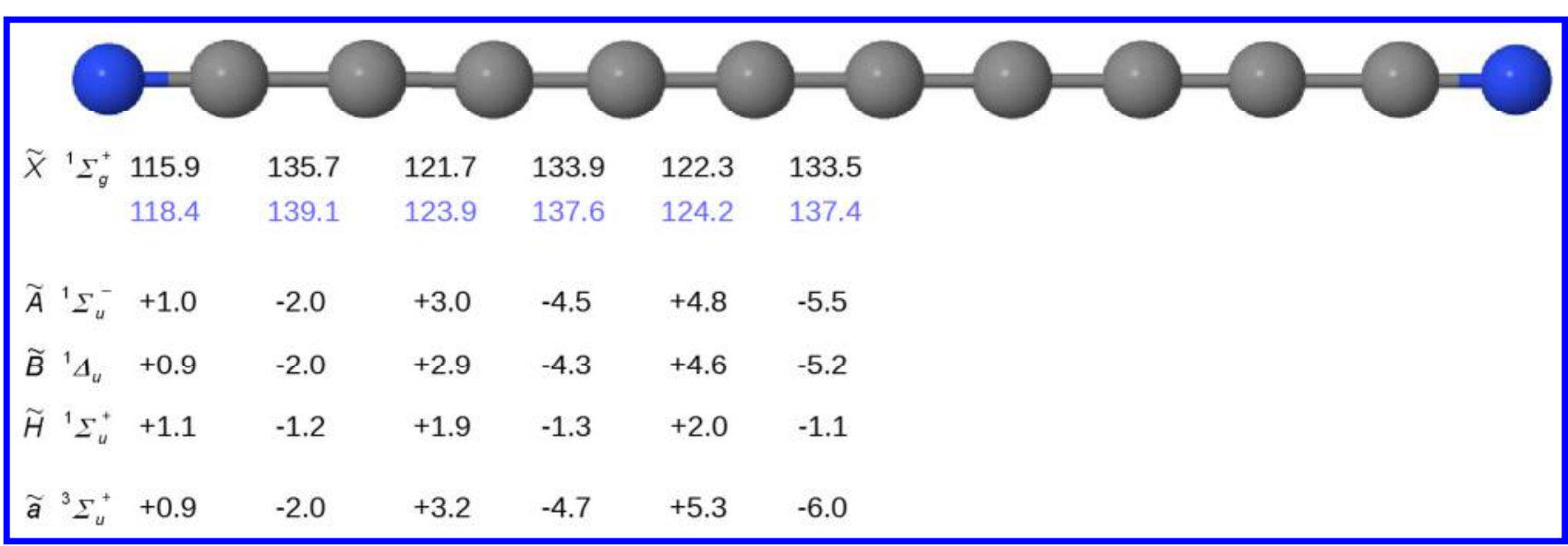

Figure 1. $\mathrm{NC}_{10} \mathrm{~N}$ geometry in its ground and selected excited electronic states as derived at the B3PW91/aug-ccpVTZ level of theory. Interatomic distances in $\mathrm{pm}$. Values listed for the excited states are relative, calculated with respect to $\widetilde{X}$. Also given (blue) are the $\operatorname{RCCSD}(T) /$ aug-cc-pVTZ predictions for the ground state ${ }^{20}$ Geometry predicted for other electronic states listed in Table 1 can be found in Figure S1 of the Supporting Information.

Table 2 lists DFT-derived wavenumbers, IR intensities and Raman activities for the vibrational modes of the ground electronic state, together with respective $\widetilde{H}$-state values (see Table $\mathrm{S} 1$ of the Supporting Information for the data concerning other excited electronic states). The visualization of vibrational modes is presented in Table S2 of the Supporting Information.

149 IR absorption measurements for $\mathrm{NC}_{10} \mathrm{~N}$ dispersed in a solid $\mathrm{NaCl}$ film ${ }^{1}$ pointed to the spectral 150 features at $2237 \mathrm{~cm}^{-1}$ (the strongest one, assigned to $\mathrm{CN}$ stretching), 2186, and $2120 \mathrm{~cm}^{-1}$; the first two match well our present prediction of the strongest IR fundamentals ( $v_{7}$ and $\left.v_{8}\right)$.

Table 2. Wavenumbers ${ }^{a}$ of Vibrational Modes $\left(\tilde{v}\right.$, in $\mathrm{cm}^{-1}$; scaled by 0.96$)$ for $\widetilde{X}^{1} \Sigma_{\mathrm{g}}^{+}$and $\widetilde{H}^{1} \Sigma_{\mathrm{u}}^{+}$Electronic States of $\mathrm{NC}_{10} \mathrm{~N}^{b}{ }^{b}$ Absolute IR Absorption Intensity (in $\mathrm{km} / \mathrm{mol}$ ) and Raman Scattering Activity (in $\AA^{4} / \mathrm{amu}$ ) Values ${ }^{a}$ for $154 \widetilde{\boldsymbol{X}}^{1} \boldsymbol{\Sigma}_{\mathrm{g}}^{+}$State.

\begin{tabular}{|c|c|c|c|c|c|}
\hline \multirow{2}{*}{ Mode } & \multirow{2}{*}{ Symmetry } & \multicolumn{5}{|c|}{$\tilde{X}$} & $\widetilde{H}$ \\
\cline { 3 - 6 } & & $\tilde{v}$ & IR intensity & Raman activity & $\tilde{v}$ \\
\hline \multicolumn{7}{|c|}{$\sigma$ symmetry } \\
\hline$v_{1}$ & $\sigma_{\mathrm{g}}$ & 2254 & 0 & 7200 & 2194 \\
\hline$v_{2}$ & $\sigma_{\mathrm{g}}$ & 2140 & 0 & 150 & 2067 \\
\hline$v_{3}$ & $\sigma_{\mathrm{g}}$ & 2115 & 0 & 74000 & 2017 \\
\hline$v_{4}$ & $\sigma_{\mathrm{g}}$ & 1414 & 0 & 25 & 1431 \\
\hline$v_{5}$ & $\sigma_{\mathrm{g}}$ & 908 & 0 & 52 & 911 \\
\hline$v_{6}$ & $\sigma_{\mathrm{g}}$ & 314 & 0 & 4.6 & 315 \\
\hline$v_{7}$ & $\sigma_{\mathrm{u}}$ & 2241 & 280 & 0 & 2174 \\
\hline$v_{8}$ & $\sigma_{\mathrm{u}}$ & 2199 & 20 & 0 & 2096 \\
\hline$v_{9}$ & $\sigma_{\mathrm{u}}$ & 2061 & 0.015 & 0 & 1941 \\
\hline$v_{10}$ & $\sigma_{\mathrm{u}}$ & 1180 & 0.016 & 0 & 1190 \\
\hline$v_{11}$ & $\sigma_{\mathrm{u}}$ & 617 & 1.1 & 0 & 621 \\
\hline \multicolumn{7}{|c|}{$\pi$ symmetry } \\
\hline$v_{12}$ & $\pi_{\mathrm{g}}$ & 554 & 0 & 146 & 509 \\
\hline$v_{13}$ & $\pi_{\mathrm{g}}$ & 512 & 0 & 1.8 & 462 \\
\hline$v_{14}$ & $\pi_{\mathrm{g}}$ & 437 & 0 & 0.55 & 392 \\
\hline$v_{15}$ & $\pi_{\mathrm{g}}$ & 222 & 0 & 0.61 & 210 \\
\hline
\end{tabular}




\begin{tabular}{|c|c|c|c|c|c|}
\hline$v_{16}$ & $\pi_{\mathrm{g}}$ & 75 & 0 & 0.091 & 75 \\
\hline$v_{17}$ & $\pi_{\mathrm{u}}$ & 561 & 3.4 & 0 & 515 \\
\hline$v_{18}$ & $\pi_{\mathrm{u}}$ & 492 & 11 & 0 & 455 \\
\hline$v_{19}$ & $\pi_{\mathrm{u}}$ & 308 & 7.0 & 0 & 288 \\
\hline$v_{20}$ & $\pi_{\mathrm{u}}$ & 142 & 11 & 0 & 139 \\
\hline$v_{21}$ & $\pi_{\mathrm{u}}$ & 28 & 5.2 & 0 & 30 \\
\hline
\end{tabular}

155

156

157

158

159

160

161

162

163

164

165

166

167

168

${ }^{a}$ Derived with harmonic approximation at the B3PW91/aug-cc-pVTZ level of theory.

${ }^{b}$ See Table S2 of the Supporting Information for the visualization of vibrational modes.

B. Electronic luminescence general trend already observed for shorter $\mathrm{NC}_{2 n} \mathrm{~N}$ molecules (see later in the text).

A strong vibronic progression beginning around $615 \mathrm{~nm}$, excited close to $260 \mathrm{~nm}$, appeared in luminescence of $\mathrm{HC}_{5} \mathrm{~N}$-doped rare gas matrices previously subjected to ArF-laser irradiations (Figure 2). The new emission can be recognized as phosphorescence of $\mathrm{NC}_{10} \mathrm{~N}$, based on (i) location of the strongest band $\left(16183 \mathrm{~cm}^{-1}\right.$ or $2.01 \mathrm{eV}$ in $\left.\mathrm{Kr}\right)$, a straightforward candidate for the vibrationless origin, matching the theoretical prediction for the $\tilde{a}^{3} \Sigma_{\mathrm{u}}^{+}-\tilde{X}^{1} \Sigma_{\mathrm{g}}^{+}$system $(2.04 \mathrm{eV}$, gas phase); (ii) vibronic spacing $\left(\sim 2140 \mathrm{~cm}^{-1}\right.$; characteristic of a triple-bond stretching); (iii) long luminescence decay time ( $4.4 \mathrm{~ms}$ in $\mathrm{Kr}$ ); (iv) the nature of precursor species (conceivably capable of doubling its heavy-atom backbone length, just as $\mathrm{HC}_{3} \mathrm{~N}$ molecules were shown to yield $\mathrm{NC}_{6} \mathrm{~N}$ ). ${ }^{21}$ Furthermore, the indicated vibrationless origin $(618 \mathrm{~nm}$ in $\mathrm{Kr}$ or $612.6 \mathrm{~nm}$ in Ar) fits well to the

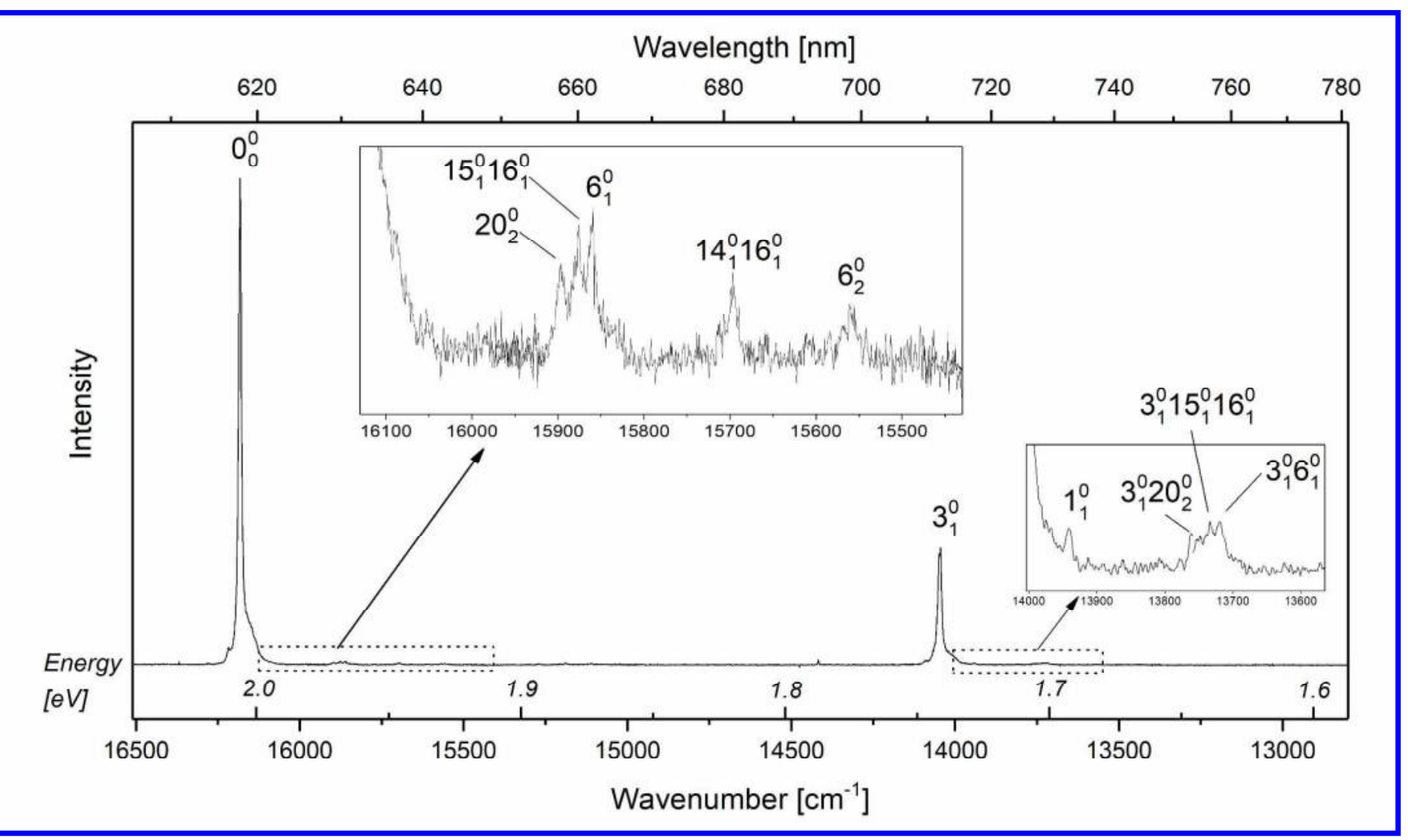

Figure 2. Luminescence, assigned to $\mathrm{NC}_{10} \mathrm{~N}$ phosphorescence, from a previously photolysed $(193 \mathrm{~nm}) \mathrm{Kr} / \mathrm{HC}_{5} \mathrm{~N}$ (1000/1) matrix, excited at $38390 \mathrm{~cm}^{-1}(4.76 \mathrm{eV}, 260.5 \mathrm{~nm})$. 
173 The observed main vibronic spacing (see Figure 2) may originate in one of the two gerade 174 stretchings, either $v_{3}$ or $v_{2}$, with DFT-predicted wavenumbers of $2115 \mathrm{~cm}^{-1}$ and $2140 \mathrm{~cm}^{-1}$, 175 respectively. Although this last value better matches the observed separation of progression 176 elements, the former is preferred, based on its particular molecular distortion pattern: alternate 177 shrinking-expansion of interatomic distances along the chain (see Table S2), qualitatively similar to 178 the geometry change experienced by $\mathrm{NC}_{10} \mathrm{~N}$ upon the transition from $\tilde{X}$ to $\tilde{a}$ (Figure 1). Moreover, 179 the $v_{3}$ stretching is distinct by its highest Raman scattering activity (see Table 2), and such modes 180 were already shown to shape the main vibronic progressions of phosphorescence emitted by shorter $181 \mathrm{NC}_{2 n} \mathrm{~N}$ molecules. ${ }^{2,21-23,57}$ Table 3 lists all vibronic bands presently identified in the $\tilde{a}^{3} \Sigma_{\mathrm{u}}^{+}-\tilde{X}^{1} \Sigma_{\mathrm{g}}^{+}$ 182 system of $\mathrm{NC}_{10} \mathrm{~N}$. The appearance of only one strong progression governed by a single mode $(\mathrm{C} \equiv \mathrm{C}$ 183 stretching), with very few other vibrations contributing to the recognized weak bands, is consistent 184 with the linearity of the lowest triplet state, predicted by DFT calculations. One can notice that in the 185 phosphorescence of $\mathrm{NC}_{2 n} \mathrm{~N}$ molecules, relative intensity of bands that do not involve the specific $186 \mathrm{C} \equiv \mathrm{C}$ stretching (analogous to $v_{3}$ here) diminishes with $n$ growing from 2 to 5 . $^{2,57}$

187 Weak phosphorescence bands appearing in $\mathrm{Kr}$ matrices, blue-shifted from the main spectral 188 features, can be clearly assigned, to a minor matrix site (origin at $16220 \mathrm{~cm}^{-1}$ ), based on 189 phosphorescence excitation spectra (see below). In Ar-matrix spectra (the Kr-Ar matrix shift is quite 190 large, see Table 3), only the strongest bands have been identified.

191 Table 3. Vibronic Bands in $\mathrm{NC}_{10} \mathbf{N}$ Phosphorescence. Relative Values Give the Distance from the Vibrationless 192 Origin.

\begin{tabular}{|c|c|c|c|c|}
\hline \multicolumn{4}{|c|}{ Wavenumber $\left[\mathrm{cm}^{-1}\right]$} & \multirow{3}{*}{ Assignment } \\
\hline \multicolumn{2}{|c|}{$\mathrm{Kr}$} & \multicolumn{2}{|c|}{$\mathrm{Ar}$} & \\
\hline Absolute & Relative & Absolute & Relative & \\
\hline 16183 & 0 & 16324 & 0 & $0_{0}^{0}$ \\
\hline 15897 & 286 & & & $20_{2}^{0}$ \\
\hline 15880 & 303 & & & $15_{1}^{0} 16_{1}^{0}$ \\
\hline 15861 & 322 & & & $6_{1}^{0}$ \\
\hline 15699 & 484 & & & $14_{1}^{0} 16_{1}^{0}$ \\
\hline $15617^{a}$ & 566 & & & $6_{1}^{0} 20_{2}^{0}$ \\
\hline $15585^{a}$ & 598 & & & $6_{1}^{0} 15_{1}^{0} 16_{1}^{0}$ \\
\hline $15562^{a}$ & 621 & & & $6_{2}^{0}$ \\
\hline 14046 & 2137 & 14186 & 2138 & $3_{1}^{0}$ \\
\hline 13941 & 2242 & & & $1_{1}^{0}$ \\
\hline 13760 & 2423 & & & $3_{1}^{0} 20_{2}^{0}$ \\
\hline 13740 & 2443 & & & $3_{1}^{0} 15_{1}^{0} 16_{1}^{0}$ \\
\hline 13720 & 2463 & & & $3_{1}^{0} 6_{1}^{0}$ \\
\hline
\end{tabular}

${ }^{a}$ Weak band, observed with wide-open monochromator slits. 
195 Table 4 collects the results of phosphorescence lifetime measurements for solid Kr-isolated mono196 and dicyanopolyynes. Within each of these families, emission lifetime markedly decreases with the 197 increase of polyyne length, a trend that may be explained considering the associated enhancement of 198 two factors promoting non-radiative $T_{1} \rightarrow S_{0}$ relaxation channels: reduction of the singlet-triplet gap 199 and the increasing number of vibrational degrees of freedom (leading to high density of states). 200 Monocyanopolyynes of Table 4 are characterized by faster phosphorescence decays than the 201 respective (i.e. isoelectronic) dicyanopolyynes, which may again be due to the higher number of 202 vibrational modes of the former. Moreover, one may point to a possible special role of large $\mathrm{CH}$ 203 stretching quanta in coupling $T_{1}$ with the ground electronic state.

204 Table 4. Phosphorescence Decay Time (in ms) for Mono- and Dicyanopolyynes Isolated in Solid Kr.

205

206

207

208

209

210

211

212

213

214

215

216

217

218

219

220

221

222

223

224

225

\begin{tabular}{|c|c|c|c|}
\hline $\mathrm{HC}_{n} \mathrm{~N}$ & $\tau$ & $\mathrm{NC}_{n} \mathrm{~N}$ & $\tau$ \\
\hline $\mathrm{HC}_{5} \mathrm{~N}^{a}$ & 40 & $\mathrm{NC}_{4} \mathrm{~N}^{b}$ & 52 \\
\hline $\mathrm{HC}_{7} \mathrm{~N}^{c}$ & 8 & $\mathrm{NC}_{6} \mathrm{~N}^{d}$ & 35 \\
\hline $\mathrm{HC}_{9} \mathrm{~N}^{e}$ & 3.9 & $\mathrm{NC}_{8} \mathrm{~N}^{d}$ & 13 \\
\hline & & $\mathrm{NC}_{10} \mathrm{~N}^{f}$ & 4.4 \\
\hline
\end{tabular}

A systematic change of electronic transition energy with the molecular size is expected to occur in homologous series (in particular those of unsaturated carbon-chain molecules) for vibrationless transitions sharing a common electronic provenance. ${ }^{59}$ Such regularities can be simplistically described either by a particle-in-a-box model (where a 'particle', i.e. an electron, is delocalized in a 'box' formed by a system of conjugated bonds) ${ }^{60}$ or by a harmonic oscillator model (with electrons oscillating within $\pi$ orbitals). ${ }^{61}$ It should then be manifested, respectively, by the linear correlation of

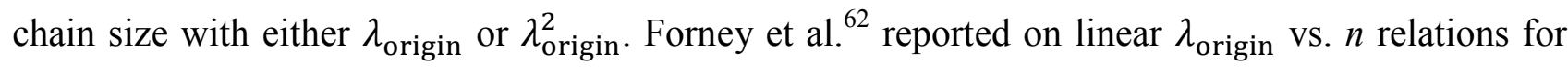
the first allowed electronic absorption systems in several series of highly unsaturated carbonbackbone molecules: $\mathrm{HC}_{2 n+1} \mathrm{~N}^{+}, \mathrm{NC}_{2 n} \mathrm{~N}^{+}, \mathrm{HC}_{2 n} \mathrm{~N}^{+}$, and $\mathrm{NC}_{2 n+1} \mathrm{~N}^{+}$. The same properties have been found for $\mathrm{C}_{2 n} \mathrm{H}^{-}, \mathrm{C}_{2 n+1} \mathrm{H}^{-}, \mathrm{HC}_{2 n} \mathrm{H}^{-}, \mathrm{HC}_{2 n+1} \mathrm{H}^{+}, \mathrm{HC}_{2 n+1} \mathrm{H}, \mathrm{C}_{2 n+1}$, and $\mathrm{C}_{2 n+1}-$ families. ${ }^{63}$ This can be rationalized in terms of a high delocalization of electrons involved in the considered transitions. On the other hand, certain curvature of $\lambda_{\text {origin }}$ vs. $n$ plots, evident for $n>4$ in the neutral polyyne $\left(\mathrm{HC}_{2 n} \mathrm{H}\right)$ series, was associated by Pino et al. ${ }^{63}$ with more pronounced localization of $\pi$ orbitals. In such cases, as demonstrated by Hausser et al. ${ }^{64}$ for diphenylpolyenes, a $\lambda_{\text {origin }}^{2}$ vs. $n$ relation (LewisCalvin plot) is expected to offer good linearity. Figure 3 presents the $\tilde{a}-\tilde{X}$ vibrationless origin wavelength data for $\mathrm{NC}_{2 n} \mathrm{~N}$, and also for the recently analyzed $\mathrm{HC}_{2 n+1} \mathrm{~N}$ series. These are neutral, closed-shell structures just as unsubstituted polyynes. Indeed, slightly better linear fits are obtained when $\lambda_{\text {origin }}^{2}(n)$ rather than $\lambda_{\text {origin }}(n)$ relation is applied. This can be best seen for the largest (5element) sequence of values collected here, i.e. dicyanopolyynes. 

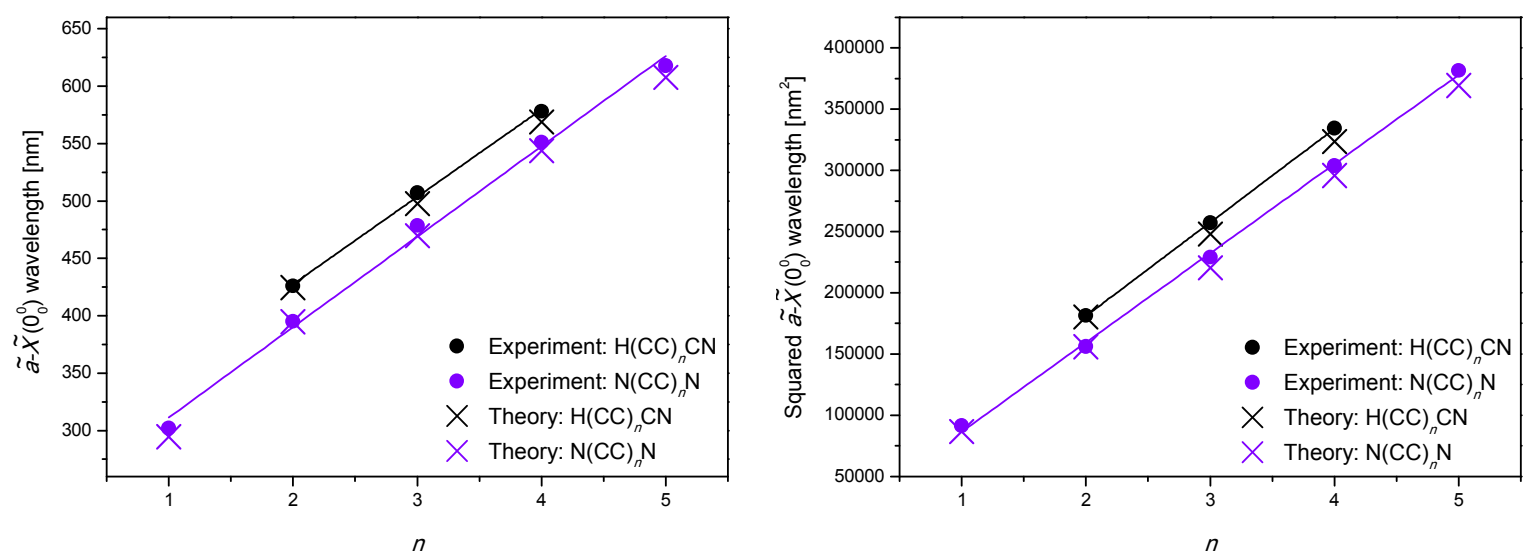

Figure 3. The dependence of phosphorescence wavelength $\lambda_{\text {origin }}$ (left panel) and $\lambda_{\text {origin }}^{2}$ (right panel) on molecular size, for the series of cyanopolyynic molecules photochemically formed in solid $\mathrm{Kr}$. Experimental values for $\mathrm{NC}_{2} \mathrm{~N}, \mathrm{NC}_{4} \mathrm{~N}, \mathrm{NC}_{6} \mathrm{~N}$, and $\mathrm{NC}_{8} \mathrm{~N}$ come from Refs. 2,21-23. Theoretical values as derived at CAMB3LYP/aug-cc-pVTZ level of theory. Experimental values were fitted with linear functions. The R2 values of fits for dicyanopolyynes are 0.999 and 0.995 for the quadratic and linear functions, respectively. Respective values for monocyanopolyynes are: 0.99997 and 0.99856 .

Lines defined by $\mathrm{NC}_{2 n} \mathrm{~N}$ and $\mathrm{HC}_{2 n+1} \mathrm{~N}$ data (Figure 3) appear to be parallel to each other (with a slope of approx. $75000 \mathrm{~nm}^{2} /$ triple bond). This can be interpreted as the inclusion of an extra $-\mathrm{C} \equiv \mathrm{C}-$ unit having the same effect in both series. It makes yet another similarity between the phosphorescence properties of respective di- and monocyano species. In case of the first fully allowed $\left({ }^{1} \Sigma_{\mathrm{u}}{ }^{+}-{ }^{1} \Sigma_{\mathrm{g}}{ }^{+}\right)$system observed for $\mathrm{NC}_{2 n} \mathrm{~N}(n=3$ to 8$)$ solutions in acetonitrile (Ref. $\left.{ }^{1}\right)$, the slope of a Lewis-Calvin plot is much lower $\left(\sim 12000 \mathrm{~nm}^{2} /\right.$ triple bond $)$ than for the presently discussed phosphorescence, reflecting differences in electronic structure of the lowest triplet $\left({ }^{3} \Sigma_{\mathrm{u}}{ }^{+}\right)$ and the lowest singlet $\left({ }^{1} \Sigma_{\mathrm{u}}^{+}\right)$state (evidenced also by their dissimilar geometries; see Figure 1).

\section{Singlet excited electronic states}

The phosphorescence excitation spectrum of $\mathrm{Kr}$ matrix-isolated $\mathrm{NC}_{10} \mathrm{~N}$ is shown in Figure 4. The first intense band falls around $38500 \mathrm{~cm}^{-1}(4.77 \mathrm{eV}, 260 \mathrm{~nm})$, in good agreement with the predicted vibrationless onset of the fully allowed $\widetilde{H}^{1} \Sigma_{\mathrm{u}}{ }^{+}-\widetilde{X}^{1} \Sigma_{\mathrm{g}}{ }^{+}$system $(4.65 \mathrm{eV})$. When identifying other vibronic bands, one should only consider the involvement of $g$-symmetry vibrations, i.e. those preserving the general $g \leftrightarrow u$ selection rule. The proposed assignments are presented in Table 5 . We identify the $\widetilde{H}$-state mode responsible for the main progression as $v_{2}$, considering that it distorts the molecule in the same way (all in-phase $\mathrm{C} \equiv \mathrm{C}$ stretches; see Table S2 of the Supporting Information) as does the $v_{3}$ mode of state $\tilde{X}$, recognized as the one shaping the vibronic structure of phosphorescence. Also, the calculated wavenumber of $\widetilde{H}$-state $v_{2}$ better matches the obtained spectral data than that of $v_{3}$. A weak distinct band observed to the red of the identified $\widetilde{H}-\tilde{X}$ origin may be tentatively interpreted as due to a lower-lying electronic state, the excitation of which could gain probability via Herzberg-Teller vibronic coupling (analogous effects were already evidenced in 
$256 \mathrm{HC}_{2 n+1} \mathrm{~N}(n=3,4)$ excitation spectra in the region of the first allowed electronic bands). ${ }^{28,33} \mathrm{Weak}$ 257 features detected to the blue of the main vibronic bands supposedly come from the coupling with 258 phonons and/or from the combination with low frequency bending modes; no reliable assignments 259 can be proposed.

260 Comparing Ar and $\mathrm{Kr}$ matrices, one can notice large differences (up to $\sim 1000 \mathrm{~cm}^{-1}$ ) in the position 261 of detected spectral features. Moreover, spectral splittings, observed in solid $\mathrm{Kr}$, coming from 262 dissimilar surroundings of embedded molecules (matrix sites) vary between 20 and $180 \mathrm{~cm}^{-1}(\mathrm{see}$ 263 Table 5). This evidence points to substantial influence of the microenvironment on electronic 264 transitions of this highly polarizable ${ }^{20}$ molecule. The role of environment was also demonstrated by 265 slightly differing band wavenumbers, from one sample to another. Due to all these effects and to the 266 high photon energy in the discussed spectral range, the error of measured wavenumber distances 267 could reach $30 \mathrm{~cm}^{-1}$. Nevertheless, systematic irregularities observed in vibronic spacing reflect the 268 contributions from anharmonic interactions. As expected, Kr-to-Ar matrix shifts are larger for $269 \widetilde{H}-\tilde{X}$ than for $\tilde{a}-\tilde{X}$ transitions. The present Kr-matrix spectrum is compared in Figure 4 with the $270 \mathrm{UV}$ absorption of $\mathrm{NC}_{10} \mathrm{~N}$ in liquid acetonitrile ${ }^{1}$ (maxima at 259, 246, 235 and $223 \mathrm{~nm}$ ). Neglecting 271 the widths of spectral features, and hence the number of resolved details, the two spectra resemble 272 one another. Moreover, just as for cryogenic matrix sample, vibronic spacings observed in liquid 273 acetonitrile are not regular. Another $\mathrm{NC}_{10} \mathrm{~N}$ absorption spectrum was reported ${ }^{25}$ for a liquid $n$-octane 274 solution, with strong absorption bands at 283, 268, 253, 243, and $232 \mathrm{~nm}$. However, an $n$-octane-to275 acetonitrile shift of approx. $-3300 \mathrm{~cm}^{-1}\left(283 \mathrm{~nm}^{25}\right.$ vs. $\left.259 \mathrm{~nm}^{1}\right)$ is unrealistic, and the attribution 276 given in Ref. ${ }^{25}$ seems to be erroneous. Additionally, a ${ }^{1} \Sigma_{\mathrm{u}}{ }^{+}-{ }^{1} \Sigma_{\mathrm{g}}{ }^{+}$origin in the vicinity of $240 \mathrm{~nm}$ 277 can be deduced for gas-phase $\mathrm{NC}_{10} \mathrm{~N}$ from the interpolation of experimental data reported in Ref. ${ }^{5}$, 278 indicating a gas-to-Kr matrix shift of ca. $-3200 \mathrm{~cm}^{-1}$. This large redshift is smaller than that due to 279 the matrix $\left(>4000 \mathrm{~cm}^{-1}\right)$ observed for the origin of allowed $\mathrm{NC}_{6} \mathrm{~N}$ absorption $\left(205 \mathrm{~nm} \mathrm{in} \mathrm{Kr}^{57}, 188\right.$ 280 nm in gas phase $\left.{ }^{65}\right)$. 


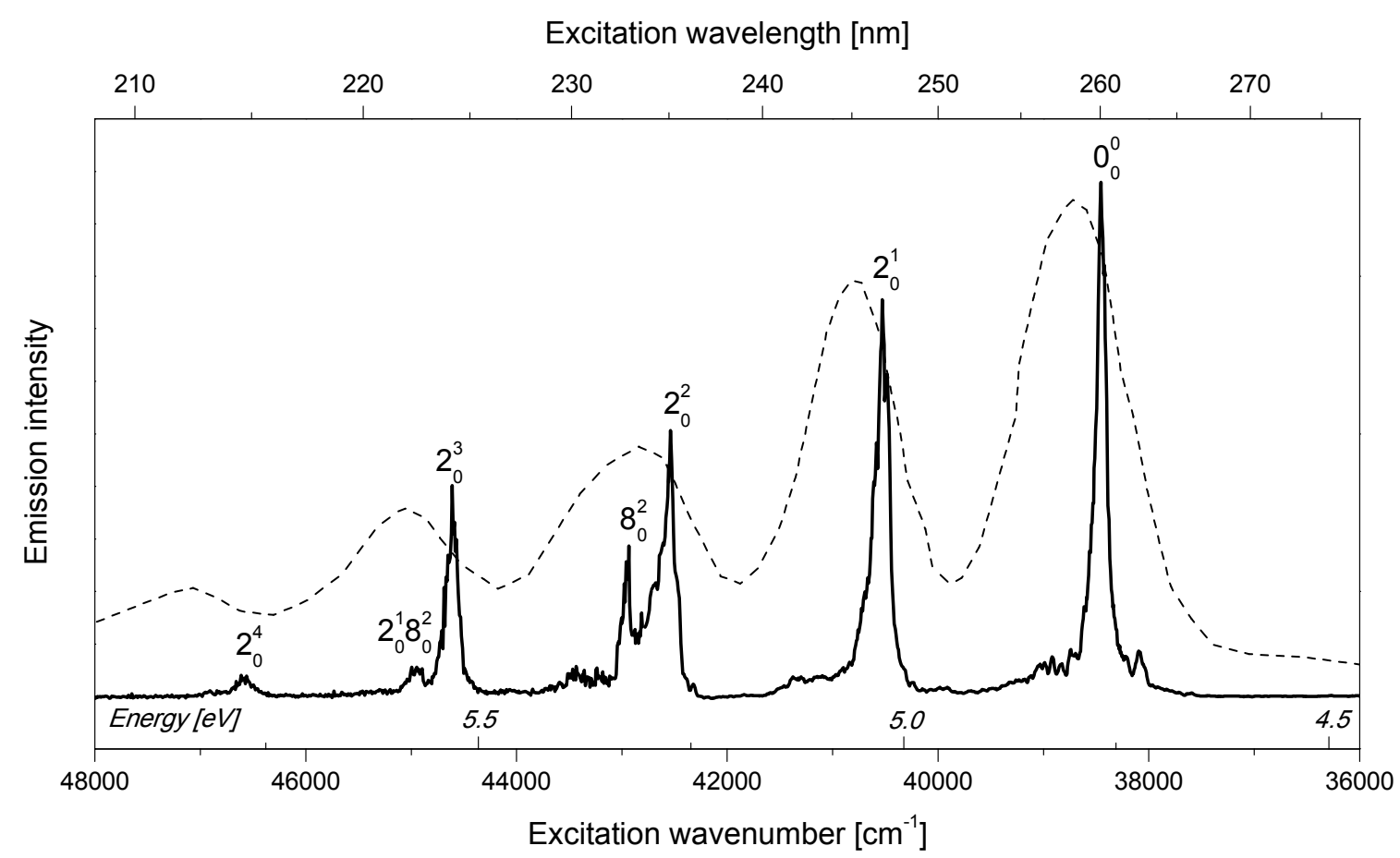

Figure 4. Excitation spectrum of luminescence assigned to $\mathrm{NC}_{10} \mathrm{~N}$ phosphorescence detected at $16183 \mathrm{~cm}^{-1}(2.01$ $\mathrm{eV}$ ), as measured for a photolyzed $(193 \mathrm{~nm}) \mathrm{Kr} / \mathrm{HC}_{5} \mathrm{~N}(1000 / 1)$ matrix. $\mathrm{UV}$ absorption spectrum of $\mathrm{NC}_{10} \mathrm{~N}$ dissolved in liquid acetonitrile (dashed trace; digitized data from Ref. ${ }^{1}$ ) is given for comparison. Variations of the excitation laser fluence could distort the measured phosphorescence intensity pattern.

Table 5. Vibronic Bands in $\mathrm{NC}_{10} \mathrm{~N}$ Phosphorescence Excitation Spectrum, due to Dipole-Allowed $\widetilde{H}^{1} \Sigma_{\mathrm{u}}^{+}-\widetilde{\boldsymbol{X}}^{1} \Sigma_{\mathrm{g}}^{+}$ Transitions. Relative Wavenumber Values Give Distances from the Preceding Progression Elements.

\begin{tabular}{|c|c|c|c|c|c|c|}
\hline \multicolumn{6}{|c|}{ Wavenumber $\left[\mathrm{cm}^{-1}\right]$} & \multirow{3}{*}{ Assignment } \\
\hline \multicolumn{2}{|c|}{$\mathrm{Kr}$ matrix, main site } & \multicolumn{2}{|c|}{ Kr matrix, minor site } & \multicolumn{2}{|c|}{ Ar matrix } & \\
\hline Absolute & Relative & Absolute & Relative & Absolute & Relative & \\
\hline 38470 & 0 & 38610 & 0 & 39430 & 0 & $0_{0}^{0}$ \\
\hline 40540 & 2070 & 40700 & 2090 & 41440 & 2010 & $22_{0}^{1}$ \\
\hline 42550 & 2010 & 42730 & 2030 & 43510 & 2070 & $2_{0}^{2}$ \\
\hline 42950 & 400 & 42970 & 240 & & & $8_{0}^{2}$ \\
\hline 44600 & 2050 & 44700 & 1970 & 45480 & 1970 & $2_{0}^{3}$ \\
\hline 44940 & 340 & 45010 & 310 & & & $22_{0}^{1} 8_{0}^{2}$ \\
\hline 46580 & 1980 & 46680 & 1980 & & & $2_{0}^{4}$ \\
\hline 46910 & 330 & & & & & $2_{0}^{2} 8_{0}^{2}$ \\
\hline
\end{tabular}

\section{Formation}

Based on previous similar considerations ${ }^{28,33}$, one can propose the following $\mathrm{NC}_{10} \mathrm{~N}$ formation scheme:

$\mathrm{HC}_{5} \mathrm{~N}+h v \rightarrow \mathrm{H}^{\bullet}+\mathrm{C}_{5} \mathrm{~N}^{\bullet}$

$\mathrm{C}_{5} \mathrm{~N}^{\bullet}+\mathrm{HC}_{5} \mathrm{~N} \rightarrow \mathrm{NC}_{10} \mathrm{~N}+\mathrm{H}^{\bullet}$

Radical recombination 
$\mathrm{C}_{5} \mathrm{~N}^{\bullet}+\mathrm{C}_{5} \mathrm{~N}^{\bullet} \rightarrow \mathrm{NC}_{10} \mathrm{~N}$

298 also has to be considered. This would be analogous to the formation of $\mathrm{NC}_{6} \mathrm{~N}$ from two $\mathrm{C}_{3} \mathrm{~N}^{\circ}$ 299 radicals, elucidated basing on the kinetics of $\mathrm{HC}_{3} \mathrm{~N}$ photolysis in rare gas matrices. ${ }^{21}$ Reaction 3 is 300 however not expected to be of chief importance here, considering the shape of the curve of growth 301 obtained for the $\mathrm{NC}_{10} \mathrm{~N}$ phosphorescence during the photolysis of $\mathrm{HC}_{5} \mathrm{~N}$ in solid $\mathrm{Kr}$ (Figure 5). If the 302 photolysis of matrix-isolated $\mathrm{HC}_{5} \mathrm{~N}$ molecules had led to $\mathrm{NC}_{10} \mathrm{~N}$ via the recombination of $\mathrm{C}_{5} \mathrm{~N}^{\circ}$ 303 radicals then, assuming the validity of arguments provided in Ref. ${ }^{21}$ (reporting on the appearance of $304 \mathrm{NC}_{6} \mathrm{~N}$ in irradiated $\mathrm{HC}_{3} \mathrm{~N}$ ), one would have seen the original increase of the dinitrile production rate 305 with photolysis time. In the present case, the production rate steadily decreases from the very onset 306 of irradiations.

307 Creation of the discussed long, all-heavy-atom chain species requires substantial mobility of the 308 involved precursor chains, apart from their dehydrogenation. Locally increased mobility of reaction 309 partners may be understood in terms of matrix "melting" resultant from the dissipation of the 310 electronic excitation energy. Other products (including mono- and dicyanopolyynes) were detected 311 in the described experiments, but it was not possible to thoroughly investigate their formation 312 efficiencies in terms of kinetics and relative quantum yields.

313 It is also possible that the precursors, instead of being dissociated into free radicals, are excited to 314 high electronic energy levels and then undergo reactions analogous to Reaction 2. In experiments 315 described here, it is not possible to differentiate between the two cases.

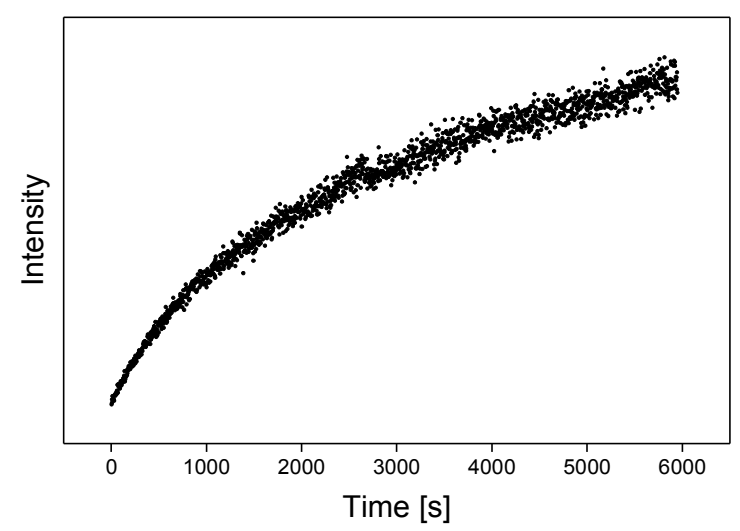

Figure 5. Time evolution of $\mathrm{NC}_{10} \mathrm{~N}$ formation, as monitored by intensity of phosphorescence emitted from irradiated $(193 \mathrm{~nm}) \mathrm{Kr}$-isolated $\mathrm{HC}_{5} \mathrm{~N}$. The abscissa represents the irradiation time.

\section{CONCLUSIONS}

The synthesis of a dicyanopolyyne chain as long as $\mathrm{NC}_{10} \mathrm{~N}$ via $\mathrm{UV}$-induced coupling of smaller molecules was observed in $\mathrm{Ar}$ and $\mathrm{Kr}$ matrices. Strong phosphorescence of $\mathrm{NC}_{10} \mathrm{~N}$ was detected. Vibronic patterns in phosphorescence and phosphorescence excitation spectra were partly interpreted with the assistance of quantum chemical calculations. Among some general trends observed in the series of cryogenic matrix-isolated $\mathrm{NC}_{2 n} \mathrm{~N}$ molecules is the lack of fluorescence, which seems to be due to efficient intersystem crossing. Phosphorescence is dominated by a 
328 vibronic progression involving a specific $\sigma_{\mathrm{g}}$ mode (an in-phase $\mathrm{C} \equiv \mathrm{C}$ stretching). With increasing 329 length of the chain:

330 (i) the wavenumber of that particular mode decreases, approaching the limit defined by the pure 331 collective $\mathrm{C} \equiv \mathrm{C}$ stretch of an infinite chain, with vanishing contributions from terminal $\mathrm{C} \equiv \mathrm{N}$ groups;

332 (ii) phosphorescence origin bands become more and more prominent; their wavelengths closely 333 follow a Lewis-Calvin relation (linearity of $\lambda_{\text {origin }}^{2}$ vs. $n$ );

334 (iii) energy of the first allowed $\left({ }^{1} \Sigma_{\mathrm{u}}{ }^{+}-{ }^{1} \Sigma_{\mathrm{g}}{ }^{+}\right)$transition decreases.

335 Vibronic progressions observed for the ${ }^{1} \Sigma_{\mathrm{u}}{ }^{+}-{ }^{1} \Sigma_{\mathrm{g}}{ }^{+}$system are governed by the same specific $\sigma_{\mathrm{g}}$ 336 stretching that shapes the phosphorescence spectrum. Its energy is lower in the excited state, 337 reflecting a decrease of the $\mathrm{C} \equiv \mathrm{C}$ bond strength, compared to the ground state.

338 Phosphorescence measurement was a detection method of choice in this study aimed at molecule 339 coupling products. The quantity of synthesized $\mathrm{C}_{10} \mathrm{~N}_{2}$ was too low to produce a detectable IR 340 signature. The reported experimental approach can presumably be adopted to synthesize and study 341 the $\mathrm{NC}_{2 n} \mathrm{~N}$ chains of $n>5$; in particular, present results permit to expect the origin of $\mathrm{NC}_{12} \mathrm{~N}$ 342 phosphorescence in solid $\mathrm{Kr}$ at about $670 \mathrm{~nm}$.

\section{ACKNOWLEDGMENTS}

This work was financially supported by the Polish National Science Centre, project no. 2011/03/B/ST4/02763, French-Polish scientific cooperation programs Partenariat Hubert-Curien Polonium (2012-2013) and PICS (2014-2016). U.S. is a beneficiary of the French Government scholarship Bourse Eiffel, managed by Campus France, and of the project "Scholarships for $\mathrm{PhD}$ students of Podlaskie Voivodeship" - the project is co-financed by European Social Fund, Polish Government and Podlaskie Voivodeship. J.-C.G. acknowledges the financial support received from the Centre National d'Etudes Spatiales (CNES) and from the French program Physique et Chimie du Milieu Interstellaire (PCMI) of CNRS/INSU with INC/INP co-funded by CEA and CNES.

\section{SUPPORTING INFORMATION AVAILABLE}

Geometry of $\mathrm{NC}_{10} \mathrm{~N}$ in several electronic states; computed IR wavenumbers for the lowest excited electronic states; visualization of vibrational modes in selected electronic states of $\mathrm{NC}_{10} \mathrm{~N}$. This information is available free of charge via the Internet at http://pubs.acs.org.

\section{REFERENCES}

(1) Schermann, G.; Grösser, T.; Hampel, F.; Hirsch, A. Dicyanopolyynes: A Homologuous Series of End-Capped Linear sp Carbon. Chem. - Eur.J. 1997, 3, 1105-1112.

(2) Turowski, M.; Crépin, C.; Couturier-Tamburelli, I.; Piétri, N.; Kołos, R. Low-Temperature Phosphorescence of Dicyanoacetylene in Rare Gas Solids. Low Temp. Phvs. 2012, 38, 723 726.

(3) Trolez, Y.; Guillemin, J.-C. Synthesis and Characterization of 2,4-Pentadiynenitrile-A Key Compound in Space Science. Angew. Chem.Int.Ed. 2005, 44, 7224-7226.

(4) Hunsmann, W. Nachweis Und Synthese Des Triacetylens. Chem.Ber. 1950, 83, 213-217. 
368

369

370

371

372

373

374

375

376

377

378

379

380

381

382

383

384

385

386

387

388

389

390

391

392

393

394

395

396

397

398

399

400

401

402

403

404

405

406

407

408

409

410

411

412

413

414

415
(5) Ding, H.; Boguslavskiy, A. E.; Schmidt, T. W.; Maier, J. P. Gas Phase Electronic Spectrum of the Nitrogen Terminated Nanowire $\mathrm{NC}_{16} \mathrm{~N}$. Chem. Phvs. Lett. 2004, 392, 225-228.

(6) Duley, W. W. Chemical Evolution of Carbonaceous Material in Interstellar Clouds. Astrophys.J. 2000, 528, 841 .

(7) Turner, B. E. Detection of Interstellar Cyanoacetylene. Astrophvs. J. Lett. 1971, 163, L35.

(8) Dickinson, D. F. Detection of Cyanoacetylene at $18 \mathrm{GHz}$. Astrophvs. Lett. 1972, 12, 235-236.

(9) McGee, R. X.; Balister, M.; Newton, L. M. Interstellar Cyanoacetylene $\mathrm{J}=2 \rightarrow 1, \mathrm{~J}=4 \rightarrow 3$ Transitions. Mon. Not.R.Astron.Soc. 1977, 180, 585-592.

(10) Gardner, F. F.; Winnewisser, G. Observations of the J $=1 \rightarrow 0$ Transitions of the (13) C Isotopic Species of Cyanoacetylene (HCCCN) in the Direction of Sagittarius B2. Astrophys. J. 1975, 197, L73.

(11) Mauersberger, R.; Henkel, C.; Sage, L. J. Dense Gas in Nearby Galaxies. III - $\mathrm{HC}_{3} \mathrm{~N}$ as an Extragalactic Density Probe. Astron. Astrophys. 1990, 236, 63-68.

(12) Bockelée-Morvan, D.; Lis, D. C.; Wink, J. E.; Despois, D.; Crovisier, J.; Bachiller, R.; Benford, D. J.; Biver, N.; Colom, P.; Davies, J. K.; et al. New Molecules Found in Comet C/1995 O1 (Hale-Bopp). Investigating the Link between Cometary and Interstellar Material. Astron.Astrophys. 2000, 353, 1101-1114.

(13) Snell, R. L.; Schloerb, F. P.; Young, J. S.; Hjalmarson, A.; Friberg, P. Observations of $\mathrm{HC}_{3} \mathrm{~N}$, $\mathrm{HC}_{5} \mathrm{~N}$, and $\mathrm{HC}_{7} \mathrm{~N}$ in Molecular Clouds. Astrophys.J. 1981, 244, 45-53.

(14) Broten, N. W.; Oka, T.; Avery, L. W.; MacLeod, J. M.; Kroto, H. W. The Detection of HC ${ }_{9} \mathrm{~N}$ in Interstellar Space. Astrophvs. J. 1978, 223, L105.

(15) Truong-Bach; Graham, D.; Nguyen-Q-Rieu. $\mathrm{HC}_{9} \mathrm{~N}$ from the Envelopes of IRC+10216 and CRL:2688. Astron. Astrophvs. 1993, 277, 133.

(16) Bell, M. B.; Avery, L. W.; MacLeod, J. M.; Matthews, H. E. The Excitation Temperature of $\mathrm{HC}_{9} \mathrm{~N}$ in the Circumstellar Envelope of IRC +10216 . Astrophvs. J. 1992, 400, 551-555.

(17) Khanna, R. K.; Perera-Jarmer, M. A.; Ospina, M. J. Vibrational Infrared and Raman Spectra of Dicyanoacetylene. Spectrochim. Acta Part Mol. Spectrosc. 1987, 43, 421-425.

(18) Agúndez, M.; Cernicharo, J.; Vicente, P. de; Marcelino, N.; Roueff, E.; Fuente, A.; Gerin, M.; Guélin, M.; Albo, C.; Barcia, A.; et al. Probing Non-Polar Interstellar Molecules through Their Protonated Form: Detection of Protonated Cyanogen $\left(\mathrm{NCCNH}^{+}\right)$. Astron. Astrophys. 2015, 579, L10.

(19) Waite, J. H.; Young, D. T.; Cravens, T. E.; Coates, A. J.; Crary, F. J.; Magee, B.; Westlake, J. The Process of Tholin Formation in Titan's Upper Atmosphere. Science 2007, 316, 870-875.

(20) Woon, D. E.; Herbst, E. Quantum Chemical Predictions of the Properties of Known and Postulated Neutral Interstellar Molecules. Astrophys. J.Suppl.Ser. 2009, 185, 273-288.

(21) Crépin, C.; Turowski, M.; Ceponkus, J.; Douin, S.; Boyé-Péronne, S.; Gronowski, M.; Kołos, R. UV-Induced Growth of Cyanopolyyne Chains in Cryogenic Solids. Phys. Chem. Chem. Phvs. PCCP 2011, 13, 16780-16785.

(22) Turowski, M.; Crépin, C.; Douin, S.; Kołos, R. Formation and Spectroscopy of Dicyanotriacetylene $\left(\mathrm{NC}_{8} \mathrm{~N}\right)$ in Solid Kr. L.Phvs. Chem.A 2014, 119, 2701-2708.

(23) Chang, J.-W.; Lee, Y.-P. The $\mathrm{C}_{2} \mathrm{~N}_{2} \widetilde{\mathrm{a}}^{3} \Sigma_{\mathrm{u}}{ }^{+}-\widetilde{\mathrm{X}}^{1} \Sigma_{\mathrm{g}}{ }^{+}$Chemiluminescence in Matrices. J. Mol. Struct. 1987, 157, 155-165.

(24) Smith, A. M.; Schallmoser, G.; Thoma, A.; Bondybey, V. E. Infrared Spectral Evidence of $\mathrm{N} \equiv \mathrm{C}-\mathrm{C} \equiv \mathrm{C}-\mathrm{N} \equiv \mathrm{C}$ : Photoisomerization of $\mathrm{N} \equiv \mathrm{C}-\mathrm{C} \equiv \mathrm{C}-\mathrm{C} \equiv \mathrm{N}$ in an Argon Matrix. J. Chem. Phys. 1993, 98, 1776-1785.

(25) Cataldo, F. Polyynes: A New Class of Carbon Allotropes. About the Formation of Dicyanopolyynes from an Electric Arc between Graphite Electrodes in Liquid Nitrogen. Polvhedron 2004, 23, 1889-1896. 
416

417

418

419

420

421

422

423

424

425

426

427

428

429

430

431

432

433

434

435

436

437

438

439

440

441

442

443

444

445

446

447

448

449

450

451

452

453

454

455

456

457

458

459

460

461

462

463

(26) Cataldo, F. Polyynes and Cyanopolyynes: Their Synthesis with the Carbon Arc Gives the Same Abundances Occurring in Carbon-Rich Stars. Orig. Life Evol. Biospheres 2006, 36, 467-475.

(27) Forte, G.; D’Urso, L.; Fazio, E.; Patanè, S.; Neri, F.; Puglisi, O.; Compagnini, G. The Effects of Liquid Environments on the Optical Properties of Linear Carbon Chains Prepared by Laser Ablation Generated Plasmas. Anpl.Surf.Sci. 2013, 272, 76-81.

(28) Szczepaniak, U.; Kołos, R.; Gronowski, M.; Chevalier, M.; Guillemin, J.-C.; Turowski, M.; Custer, T.; Crépin, C. Cryogenic Photochemical Synthesis and Electronic Spectroscopy of Cyanotetracetylene. L.Phvs. Chem.A 2017, 121, 7374-7384.

(29) Agreiter, J.; Smith, A. M.; Härtle, M.; Bondybey, V. E. Laser-Induced Fluorescence of Matrix-Isolated $\mathrm{C}_{4} \mathrm{~N}_{2}{ }^{+}$. Chem. Phvs. Lett. 1994, 225, 87-96.

(30) Agreiter, J.; Smith, A. M.; Bondybey, V. E. Laser-Induced Fluorescence of Matrix-Isolated $\mathrm{C}_{6} \mathrm{~N}_{2}{ }^{+}$and of $\mathrm{C}_{8} \mathrm{~N}_{2}{ }^{+}$. Chem. Phvs. Lett. 1995, 241, 317-327.

(31) Coupeaud, A.; Kołos, R.; Couturier-Tamburelli, I.; Aycard, J. P.; Piétri, N. Photochemical Synthesis of the Cyanodiacetylene $\mathrm{HC}_{5} \mathrm{~N}$ : A Cryogenic Matrix Experiment. J. Phys. Chem. A 2006, 110, 2371-2377.

(32) Couturier-Tamburelli, I.; Piétri, N.; Crépin, C.; Turowski, M.; Guillemin, J.-C.; Kołos, R. Synthesis and Spectroscopy of Cyanotriacetylene $\left(\mathrm{HC}_{7} \mathrm{~N}\right)$ in Solid Argon. J. Chem. Phys. 2014, 140, 044329.

(33) Szczepaniak, U.; Kołos, R.; Gronowski, M.; Guillemin, J.-C.; Crépin, C. Low Temperature Synthesis and Phosphorescence of Methylcyanotriacetylene. L.Phvs.Chem A 2018, 122, 8999.

(34) Parr, R. G.; Yang, W. Density-Functional Theory of Atoms and Molecules; Oxford University Press, 1989.

(35) Frisch, M. J.; Trucks, G. W.; Schlegel, H. B.; Scuseria, G. E.; Robb, M. A.; Cheeseman, J. R.; Scalmani, G.; Barone, V.; Mennucci, B.; Petersson, G. A.; et al. Gaussian 09 Rev. B.01; Gaussian, Inc.: Wallingford, CT, USA, 2009.

(36) Bauernschmitt, R.; Ahlrichs, R. Treatment of Electronic Excitations within the Adiabatic Approximation of Time Dependent Density Functional Theory. Chem. Phys. Lett. 1996, 256, 454-464.

(37) Casida, M. E.; Jamorski, C.; Casida, K. C.; Salahub, D. R. Molecular Excitation Energies to High-Lying Bound States from Time-Dependent Density-Functional Response Theory: Characterization and Correction of the Time-Dependent Local Density Approximation Ionization Threshold. L.Chem. Phvs. 1998, 108, 4439-4449.

(38) Stratmann, R. E.; Scuseria, G. E.; Frisch, M. J. An Efficient Implementation of TimeDependent Density-Functional Theory for the Calculation of Excitation Energies of Large Molecules. L. Chem. Phvs. 1998, 109, 8218-8224.

(39) Perdew, J. P.; Ziesche, P.; Eschrig, H. Electronic Structure of Solids' 91; Akademie Verlag, Berlin, 1991; Vol. 11.

(40) Perdew, J. P.; Chevary, J. A.; Vosko, S. H.; Jackson, K. A.; Pederson, M. R.; Singh, D. J.; Fiolhais, C. Atoms, Molecules, Solids, and Surfaces: Applications of the Generalized Gradient Approximation for Exchange and Correlation. Phvs.Rev. B 1992, 46, 6671-6687.

(41) Perdew, J. P.; Chevary, J. A.; Vosko, S. H.; Jackson, K. A.; Pederson, M. R.; Singh, D. J.; Fiolhais, C. Erratum: Atoms, Molecules, Solids, and Surfaces: Applications of the Generalized Gradient Approximation for Exchange and Correlation. Phys. Rev. B 1993, 48, 4978-4978.

(42) Perdew, J. P.; Burke, K.; Wang, Y. Generalized Gradient Approximation for the ExchangeCorrelation Hole of a Many-Electron System. Phvs. Rev. B 1996, 54, 16533-16539. 
464 (43) Yanai, T.; Tew, D. P.; Handy, N. C. A New Hybrid Exchange-correlation Functional Using

465

466

467

468

469

470

471

472

473

474

475

476

477

478

479

480

481

482

483

484

485

486

487

488

489

490

491

492

493

494

495

496

497

498

499

500

501

502

503

504

505

506

507

508

509

510

511

512 the Coulomb-Attenuating Method (CAM-B3LYP). Chem. Phvs. Lett. 2004, 393, 51-57.

(44) Dunning, T. H. J. Gaussian Basis Sets for Use in Correlated Molecular Calculations. I. The Atoms Boron through Neon and Hydrogen. J. Chem. Phvs. 1989, 90, 1007-1023.

(45) Kendall, R. A.; Jr, T. H. D.; Harrison, R. J. Electron Affinities of the First $\square$ row Atoms Revisited. Systematic Basis Sets and Wave Functions. L.Chem. Phvs. 1992, 96, 6796-6806.

(46) Andersson, M. P.; Uvdal, P. New Scale Factors for Harmonic Vibrational Frequencies Using the B3LYP Density Functional Method with the Triple- $\zeta$ Basis Set 6-311+G(d,P). J. Phys. Chem. A 2005, 109, 2937-2941.

(47) Merrick, J. P.; Moran, D.; Radom, L. An Evaluation of Harmonic Vibrational Frequency Scale Factors. J. Phvs. Chem. A 2007, 111, 11683-11700.

(48) Foresman, J. B.; Head-Gordon, M.; Pople, J. A.; Frisch, M. J. Toward a Systematic Molecular Orbital Theory for Excited States. L.Phvs. Chem. 1992, 96, 135-149.

(49) Christiansen, O.; Koch, H.; Jørgensen, P. The Second-Order Approximate Coupled Cluster Singles and Doubles Model CC2. Chem. Phvs. Lett. 1995, 243, 409-418.

(50) Christiansen, O.; Koch, H.; Halkier, A.; Jo/rgensen, P.; Helgaker, T.; Merás, A. S. de. Large $\square$ scale Calculations of Excitation Energies in Coupled Cluster Theory: The Singlet Excited States of Benzene. L. Chem. Phvs. 1996, 105, 6921-6939.

(51) Christiansen, O.; Halkier, A.; Koch, H.; Jo/rgensen, P.; Helgaker, T. Integral-Direct Coupled Cluster Calculations of Frequency-Dependent Polarizabilities, Transition Probabilities and Excited-State Properties. J.Chem. Phvs. 1998, 108, 2801-2816.

(52) Hald, K.; Hättig, C.; Jørgensen, P. Triplet Excitation Energies in the Coupled Cluster Singles and Doubles Model Using an Explicit Triplet Spin Coupled Excitation Space. J. Chem. Phys. 2000, 113, 7765-7772.

(53) Aidas, K.; Angeli, C.; Bak, K. L.; Bakken, V.; Bast, R.; Boman, L.; Christiansen, O.; Cimiraglia, R.; Coriani, S.; Dahle, P.; et al. The Dalton Quantum Chemistry Program System. Wilev Interdiscip. Rev. Comput. Mol. Sci. 2014, 4, 269-284.

(54) Angeli, C.; Bak, K. L.; Bakken, V.; Christiansen, O.; Cimiraglia, R.; Coriani, S.; Dahle, P.; Dalskov, E. K.; Enevoldsen, T.; Fernandez, B.; et al. Dalton, a Molecular Electronic Structure Program, Release Dalton2016.2 (2016), see http://Daltonprogram.org.

(55) Zhurko, G. Chemcraft - Graphical program for visualization of quantum chemistry computations http://chemcraftprog.com/.

(56) Turowski, M.; Szczepaniak, U.; Custer, T.; Gronowski, M.; Kołos, R. Electronic Spectroscopy of Methylcyanodiacetylene $\left(\mathrm{CH}_{3} \mathrm{C}_{5} \mathrm{~N}\right)$. ChemPhvsChem 2016, 17, 4068-4078.

(57) Turowski, M. Niskotemperaturowe Badania Fotochemii i Spektroskopii Cyjanoacetylenów o Znaczeniu Astrofizycznym. PhD Dissertation, Institute of Physical Chemistry, Polish Academy of Sciences, Warsaw, 2012.

(58) Turowski, M.; Crépin, C.; Gronowski, M.; Guillemin, J.-C.; Coupeaud, A.; CouturierTamburelli, I.; Piétri, N.; Kołos, R. Electronic Absorption and Phosphorescence of Cyanodiacetylene. L. Chem. Phvs. 2010, 133, 074310-074310.

(59) Murrell, J. N. The Theory of the Electronic Spectra of Organic Molecules; Methuen \& Co. Ltd: Lomdon, U.K., 1963.

(60) Kuhn, H. A Quantum $\square$ Mechanical Theory of Light Absorption of Organic Dyes and Similar Compounds. J. Chem. Phvs. 1949, 17, 1198-1212.

(61) Lewis, G. N.; Calvin, M. The Color of Organic Substances. Chem.Rev. 1939, 25, 273-328.

(62) Forney, D.; Freivogel, P.; Fulara, J.; Maier, J. P. Electronic Absorption Spectra of Cyano $\square$ substituted Polyacetylene Cations in Neon Matrices. J.Chem.Phvs. 1995, 102, 1510-1514.

(63) Pino, T.; Ding, H.; Güthe, F.; Maier, J. P. Electronic Spectra of the Chains $\mathrm{HC}_{2 n} \mathrm{H}(n=8-13)$ in the Gas Phase. L.Chem. Phvs. 2001, 114, 2208-2212. 
513 (64) Hausser, K. W.; Kuhn, R.; Seitz, G. Lichtabsorption Und Doppelbindung. V. Über Die 514 Absorption von Verbindungen Min Konjugierten Kohlenstoffdoppelbindungen Bei Tiefer Temperatur. Z Phys. Chem Abt B 1935, 29, 391.

(65) Connors, R. E.; Roebber, J. L.; Weiss, K. Vacuum Ultraviolet Spectroscopy of Cyanogen and Cyanoacetylenes. L.Chem. Phvs. 1974, 60, 5011-5024. 


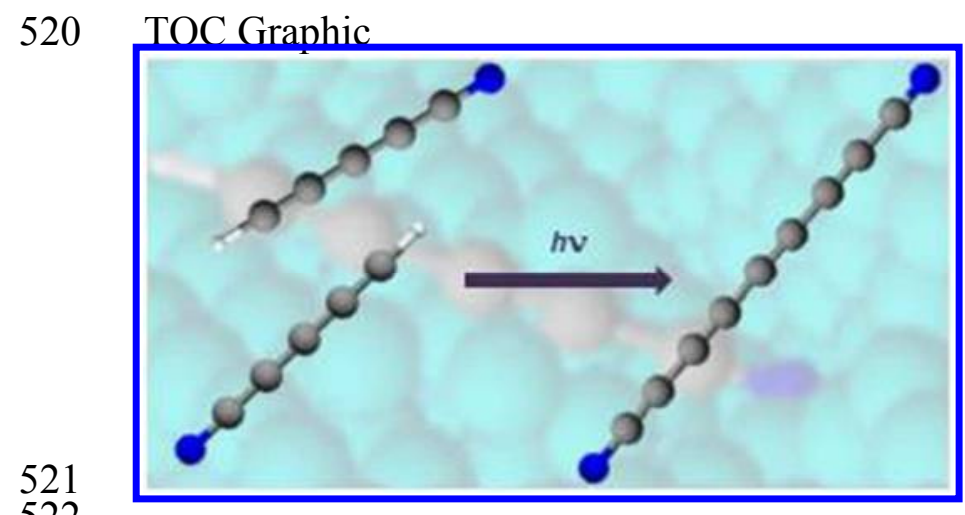

522 